\title{
A investigação de teatro num mundo digital
}

\author{
Marvin Carlson
}
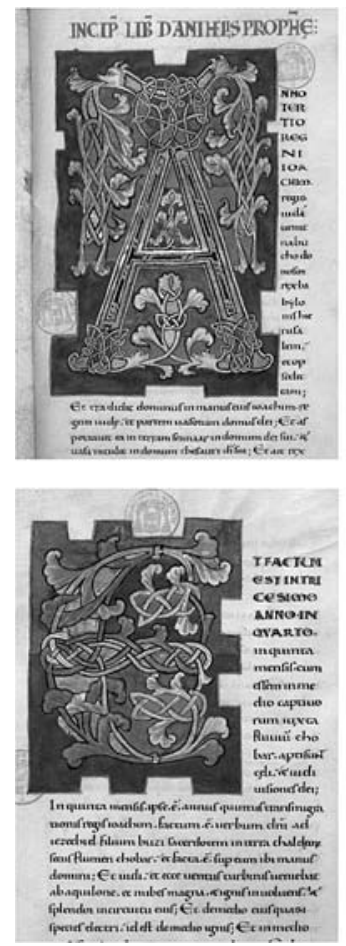
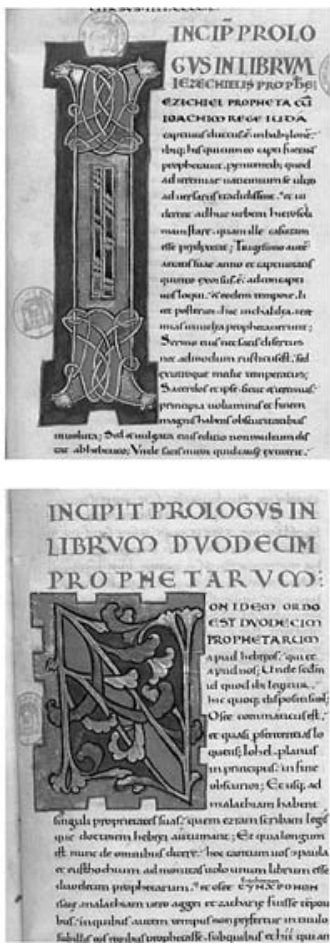

Durante a maior parte da minha carreira como investigador de teatro, trabalhei com materiais agora descritos como informação analógica, sobretudo livros e papéis, completados por imagens visuais dos mais diversos tipos. Os resultados desta investigação estavam então, na sua maioria, limitados a formas de preservação e circulação novamente analógicas, sobretudo artigos e livros. Contudo, à medida que o século XX se aproximava do seu término, fui-me apercebendo que, tal como acontecia com a maior parte dos meus colegas, eu estava cada vez mais a trabalhar e a viver num mundo digital. Isto começou por afectar o acto da escrita, ao passar da máquina de escrever para o processador de texto, enquanto a minha investigação continuava predominantemente limitada a fontes não digitais.

Contudo, gradualmente, fui-me apercebendo que a digitalização começou a afectar cada vez a minha própria investigação. Inicialmente, esta situação limitou-se sobretudo à verificação de factos ou à recolha de informação objectiva. Precisava da data de nascimento de alguém, da informação bibliográfica sobre um livro ou de uma qualquer informação factual, o tipo de coisa que anteriormente eu resolveria através da consulta de um dicionário, de uma enciclopédia ou qualquer outra obra de referência. Dei-me conta que,
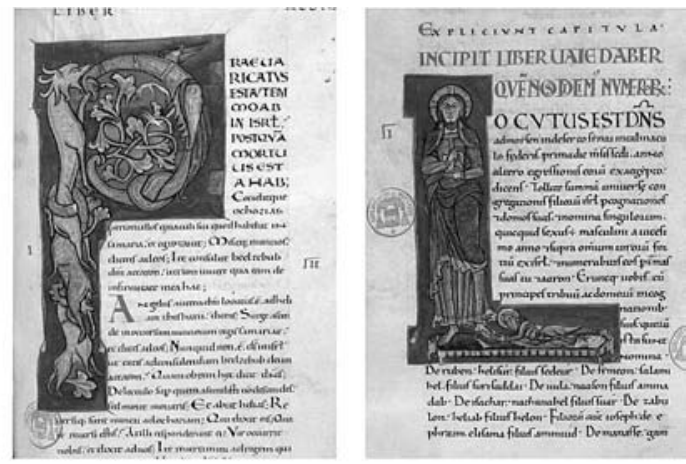

http://liberfloridus cines.fr

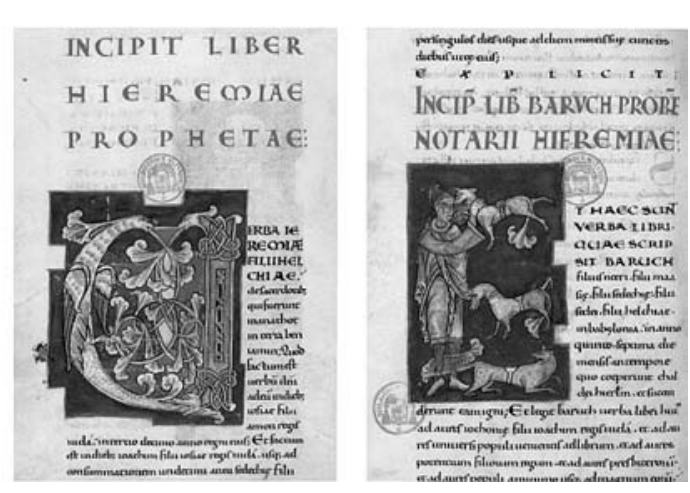

cada vez mais, a consulta dessas informações em forma digital através da internet se revelava rápida e mais eficiente. Claro que a ausência de controlos editoriais na internet implicava encarar a informação aí colocada com maior cautela, mas a facilidade de acesso compensava largamente essa limitação. Se andava à procura de informação sobre algum trabalho mais recente, a internet mostrava-se ainda mais valiosa. Material sobre artistas e espectáculos demasiado contemporâneos para poderem ter já aparecido na minha biblioteca aparecia quase instantaneamente disponivel sob forma digital. Se, por exemplo, eu estava interessado num encenador europeu contemporâneo, a informação biográfica impressa sobre ele, quando disponivel, tendia a estar já muito desactualizada, enquanto que a internet conseguia muitas vezes dizer-me o que esse artista andava a encenar até ao seu trabalho mais recente.

À medida que cada vez mais informação analógica vai sendo convertida em suporte digital, esta facilidade de acesso torna-se cada vez maior. Enquanto que até há alguns anos atrás eu poderia servir-me do meu computador em lugar de me dirigir à minha estante ou de ir à biblioteca para consultar um dicionário, uma enciclopédia, um qualquer livro de história ou alguma obra mais 
especializada, actualmente, em muitas situações, eu posso usar o meu computador em lugar de viajar até algum pais distante para consultar um arquivo especial. Muitas das principais bibliotecas do mundo estão agora a digitalizar as suas colecções de manuscritos. Por exemplo, o estudioso de teatro medieval pode consultar uma base de dados francesa que inclui 1.600 manuscritos e 31.000 imagens das bibliotecas Mazarine e Sainte-Geneviéve em Paris', e projectos semelhantes estão em curso na Biblioteca Nacional da Holanda, na Biblioteca Nacional de Paris e na Biblioteca Britânica. Até este momento, os recursos deste tipo disponiveis on-line têm-se dedicado predominantemente a equivalentes digitais do material analógico tradicional, mas uma vez que as imagens em movimento e o som podem ser armazenados digitalmente com tanta facilidade como as reproduções visuais de documentos, torna-se claro que os estudantes de teatro e os investigadores muito em breve terão acesso, e com a mesma facilidade, a registos visuais de espectáculos reais ou reconstruídos. Usando mais uma vez o teatro medieval como exemplo, poderíamos referir a "mostra de vídeo" intitulada "Performing Medieval Narrative Today" ("Representando a Narrativa Medieval Hoje"), criada pelo Studio for Digital Projects and Research da Universidade de Nova lorque. Este sitio ${ }^{2}$ oferece neste momento, para além de materiais bibliográficos e outros, uma colecção de 25 itens, mas com tendência para aumentar, de sequências em vídeo de diversos minutos de duração que nos mostram actores, contadores de histórias, cantores, músicos, mimos, marionetistas e bailarinos apresentando uma ampla variedade de textos medievais. Um tipo muito diferente de arquivo digital é aquele que está a ser desenvolvido também na Universidade de Nova lorque pelo Hemispheric Institute of Performance and Politics. Uma colecção inicial de 20 sequências em vídeo, incluindo entrevistas e breves excertos de espectáculos, foi criada em 2001, e tem vindo a aumentar de forma regular. 0 objectivo é desenvolver uma base de dados para a documentação de espectáculos da América do Norte e do $\mathrm{Sul}^{3}$.

Os historiadores que trabalham regularmente com arquivos, na sua maioria, ainda insistem que mesmo a mais rigorosa reprodução digital não é nunca um substituto perfeito do manuscrito, capaz de veicular informação ao investigador mais sensivel que escapa à reprodução digital, e o registo digital de espectáculos específicos, tanto históricos como contemporâneos, é susceptível do mesmo tipo de críticas de selectividade que têm sido dirigidas à reprodução fílmica de peças de teatro. Embora reconheça a validade destas reservas, tenho também consciência das complexidades da recepção neste tipo de situações, pela primeira vez brilhantemente discutidas por Walter Benjamin no seu estudo clássico "A obra de arte na era da reprodução mecânica". Não há qualquer dúvida de que a reprodução digital de um manuscrito o priva da sua aura benjaminiana. A extensão exacta em que isto interfere com a sua utilização pelo investigador é ainda uma questão em aberto. Contudo, não há qualquer dúvida de que seja lá qual for a perda envolvida, a reprodução digital apresenta-se como suficientemente rigorosa para revolucionar o modo como a maior parte dos investigadores se relaciona com aquilo que costumava ser designado como material primário.

Sejam lá quais forem as suas limitações enquanto reprodução, esta digitalização de arquivos é actualmente um fenómeno tão alargado que se tornou já algo completamente aceite pelo mundo actual da investigação. Regressarei a esta questão mais tarde nas minhas observações gerais sobre alguns dos problemas apresentados pela digitalização, mas gostaria agora de passar deste aspecto ligado ao efeito da digitalização sobre a investigação de teatro para alguns outros aspectos muito diferentes deste fenómeno, mais recentes na sua origem e que só agora estão a começar a produzir algum impacto no modo como os estudantes estudam a história do teatro e no modo como os académicos o investigam e apresentam os resultados da sua investigação.

0 desenvolvimento tecnológico mais intimamente relacionado com a metodologia de investigação tradicional envolve a criação de meta-dados ou de arquivos de hipertexto. 0 teatro é uma área de investigação particularmente bem adequada a esta espécie de estudo tecnológico porque qualquer espectáculo pode ser encarado de uma imensa variedade de perspectivas. Um pioneiro importante neste tipo de trabalho foi o Professor John Wolcott, da Universidade de Washington, que começou em 1984 a trabalhar no projecto Olympus, apoiado pela IBM e dedicado a pesquisar a utilização da tecnologia informática na educação. 0 seu primeiro grande projecto, em 1986 e 1987, foi a reconstrução digital de um entretenimento da corte inglesa do século XVII, Florimene, sobre o qual sobrevive um número considerável de desenhos e descrições. Para criar um espaço tridimensional gerado por computador, serviram-se de uma forma inicial do CADD (Computer Assisted Drafting and Design), o tipo de programa que nestes últimos vinte anos conheceu um desenvolvimento assinalável, atingindo um grau de sofisticação que permite a inclusão de figuras em movimento em ambientes extraordinariamente pormenorizados, bem familiares no mundo actual dos jogos de computador.

Wolcott e os seus alunos expandiram o seu trabalho colaborando com uma companhia de software instalada perto da Universidade que se especializara em programas CADD. Desenvolveram modelos digitais tridimensionais de diversos teatros históricos, tais como o teatro helénico em Pergamon, discutidos num artigo publicado em 1990 na Theatre Design and Technology, intitulado "Learning Theatre History in the 3rd Dimension" (Wolcott 1990). Um projecto semelhante, mas ainda mais ambicioso, foi lançado na Europa em 1998 por um consórcio de académicos europeus e de peritos informáticos liderados pela Universidade de Warwick, em Inglaterra ${ }^{4}$. Este projecto, 
chamado Theatron e apoiado pela Comissão Europeia, já criou até à data modelos virtuais de dezasseis importantes espaços teatrais europeus, incluindo exemplos clássicos como os teatros de Dioniso, de Epidauro e de Pompeia, teatros de feira e cortejos medievais, teatros renascentistas como o Sabbioneta e o Globo londrino, teatros setecentistas e oitocentistas como os de Drottningholm e de Bayreuth, e exemplos do século XX como o Vieux-Colombier, em Paris, e a Schaubühne am Lehninerplatz, em Berlim.

Hugh Denard, ligado ao projecto Theatron, sugeriu uma vasta tipologia de documentação no domínio das artes do espectáculo, dividida em quatro tipos básicos: texto (incluindo textos dramáticos e registos de arquivo), descrições (incluindo pinturas, desenhos e notações coreográficas), gravações (incluindo fotografias, filme e vídeo) e simulações (envolvendo o espaço e a representação). Os dois primeiros destes quatro tipos de documentação têm sido as ferramentas tradicionais da história do teatro, uma vez que a tecnologia de gravação é de origem muito recente. As simulações, por seu lado, asseguram um tipo muito distinto de conhecimento histórico, próximo da experiência concreta que está, na realidade, na base do teatro. Até muito recentemente, as simulações de teatros históricos eram algo muito raro, devido às dificuldades e aos custos desse tipo de projectos, embora tenham constituído uma parte significativa, ainda que menor, da história do teatro, desde o inicio do Renascimento italiano, quando o Teatro Olímpico procurou reconstruir um teatro clássico, até às mais recentes reconstruções do Globo isabelino em Inglaterra, nos Estados Unidos, na Alemanha e no Japão.

A tecnologia digital de projectos como o Theatron oferece uma abordagem alternativa a este tipo de documentação tridimensional, através da criação de espaços virtuais que asseguram a um qualquer utilizador do sítio disponivel na internet a mesma liberdade de movimentos e de perspectivas proporcionada por uma reconstrução física. Embora a experiência real da representação não possa ser duplicada, Denard defende que os espaços virtuais oferecem vantagens que claramente compensam estas limitações. Para além do custo envolvido na construção de réplicas em tamanho real de teatros históricos, como o Globo londrino, uma vez construídas é difícil modificar essas estruturas em resposta ao aparecimento de novos dados ou de novas perspectivas fornecidas pela investigação, e mais difícil ainda conseguir que elas reflictam interpretações distintas dos dados históricos disponiveis. As reconstruções virtuais, por outro lado, "podem ser rapidamente modificadas, acompanhadas de hipóteses alternativas", e, mais importante ainda, "podem ser distribuidas mundialmente, permitindo a sua utilização simultânea e colectiva por utilizadores espacialmente separados entre si" (Denard 2004: 59).

Até este momento, o Theatron, à imagem do projecto Florimene de Washington, tem-se ocupado unicamente da criação virtual de espaços teatrais, mas outros projectos têm-se servido do trabalho entretanto desenvolvido para criar projectos muito mais complicados e ambiciosos no domínio da digitalização da história do teatro. Mais uma vez, Wolcott em Washington foi responsável por um modelo pioneiro desse tipo de trabalho. A seguir ao projecto Florimene, ele avançou, em finais dos anos oitenta, com o muito mais ambicioso projecto Philadelphia, concebido com base no primeiro edifício de teatro destinado a espectáculos profissionais construido nos Estados Unidos, o Chestnut Street Theatre, construído em Filadélfia em 1794. Trabalhando a partir da planta baixa, dos alçados, de esboços e relatos de contemporâneos, Wolcott e os seus colaboradores dedicaram quatro anos a criar uma pormenorizada reconstrução virtual em três dimensões deste famoso teatro. À medida que o projecto foi evoluindo, outros investigadores foram chamados a colaborar, nomeadamente os curadores da colecção de têxteis da Henry Art Gallery, desenvolvendo ligações do modelo do teatro a centenas de exemplos de vestimentas masculinas e femininas que poderão ter sido então utilizadas tanto pelos actores como pelos espectadores do teatro original.

Com uma mais directa e imediata relevância para a história do teatro, o projecto Philadelphia desenvolveu oito breves "cenas" nas quais é possivel ver os actores, envergando figurinos historicamente rigorosos, a representar em cenários de época, tal como aqueles que teriam sido utilizados no teatro original. As imagens de fundo foram extraídas de um teatro de papel britânico do século XIX e os actores foram inseridos electronicamente sobre esses fundos. 0 projecto Philadelphia nunca foi desenvolvido num pacote comercial, em resultado de problemas ligados a autorizações, financiamentos e tempos de execução. 0 próprio Wolcott caracterizou este trabalho como simplesmente exploratório, deixando para outros o seu desenvolvimento. No início do século XXI, à medida que a tecnologia digital se mostra cada vez mais acessivel e sofisticada e a criação de ambientes virtuais e de acção virtual mais desenvolvida e aperfeiçoada, um vasto número de investigadores estão agora empenhados em continuar o trabalho pioneiro de investigadores como Wolcott. 0 campo da Simulação de Espectáculos ao Vivo (Live Performance Simulation) apresenta-se actualmente como uma das mais ambiciosas e excitantes áreas da investigação contemporânea em história do teatro.

Um notável exemplo actual deste tipo de investigação é o projecto Virtual Vaudeville, conduzido por David Z. Saltz, o fundador e director do Interactive Performance Laboratory, da Universidade da Georgia. Este projecto começou em Setembro de 2000 no âmbito de um seminário apoiado pela National Initiative for a Networked Cultural Heritage (NINCH). A NINCH foi criada em 1993 como uma associação sem fins lucrativos de organizações na área das artes, das humanidades e das ciências sociais, empenhada em assegurar a liderança no domínio da evolução dos ambientes digitais. As organizações financiadoras foram o American Council of Learned 

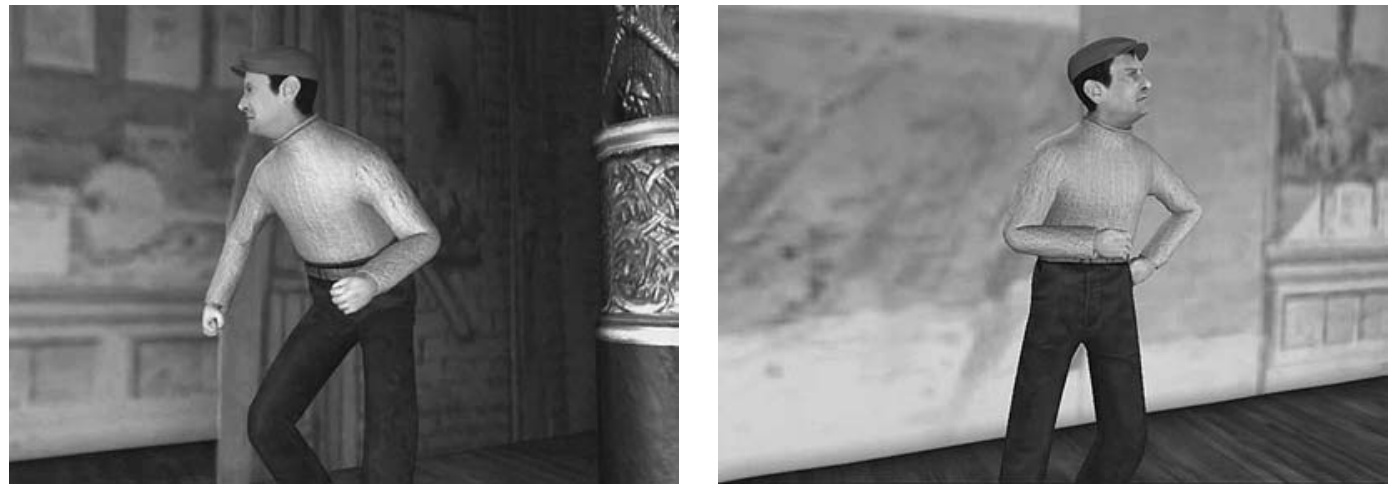

Societies, a Coalition for Networked Information e o Getty Information Institute, parte do J. Paul Getty Trust ${ }^{5}$. Deste seminário saiu aquilo que recebeu o nome de Sistema de Simulação de Espectáculos ao Vivo (Live Performance Simulation System), concebido para recriar espectáculos históricos em ambientes de realidade virtual semelhantes àqueles que encontramos num jogo de computador em três dimensões. Diversos académicos de sete universidades americanas têm estado envolvidos neste projecto. 0 grupo inclui especialistas em animação tridimensional para computador, programação e concepção de modelos, bem como artistas e investigadores ligados ao teatro e à música: Charles B. Davis, da Georgia, Bruce McConachie, de Pittsburgh, e Susan Kattwinkel, de Charleston, todos eles especialistas no teatro popular americano do século XIX, o musicologista Larry Wooster, de Denver, o cenógrafo Frank Mohler, e Faniel Zellner, do Studio Z, de Chicago, encarregado de escrever o diálogo para personagens interactivas colocadas em bastidores e entre o público.

O Sistema de Simulação de Espectáculos ao Vivo baseiase nas mesmas premissas do projecto Theatron - de que as reconstruções em realidade virtual evitam alguns dos problemas sérios das reconstruções físicas e reais como a do Globo londrino, nomeadamente o enorme investimento financeiro, a sua inflexibilidade física e a limitação da acessibilidade a pessoas que se encontrem num determinado local. Contudo, enquanto o Theatron, pelo menos até este momento, só conseguiu assegurar visitas virtuais a teatros históricos, o Sistema de Simulação de Espectáculos ao Vivo optou por prosseguir o caminho sugerido pelo projecto Philadelphia, de Wolcott, colocando actores virtuais no palco em situação de espectáculo, mas avançando ainda mais ao acrescentar a toda a experiência a inclusão de pessoal de apoio e de espectadores virtuais. 0 objectivo é uma experiência teatral total, superior aos registos fílmico ou videográfico - limitados a uma única perspectiva, enquanto que um verdadeiro espectador pode olhar para onde quiser, mesmo para algo que não está no palco - e também superior à espécie de completa imersão proporcionada por uma qualquer reconstrução moderna, como a do Globo londrino, na qual o espectador tem a total liberdade de perspectiva de uma experiência teatral real, embora olhando à sua volta veja unicamente um palco e um auditório que procuram reproduzir um teatro passado enquanto que os actores e o restante pessoal, bem como os espectadores, surgem todos como visitantes anacrónicos do século XXI.

Para o seu primeiro grande projecto, intitulado Virtual Vaudeville, os investigadores decidiram recriar este exemplo de entretenimento popular americano tal como teria sido

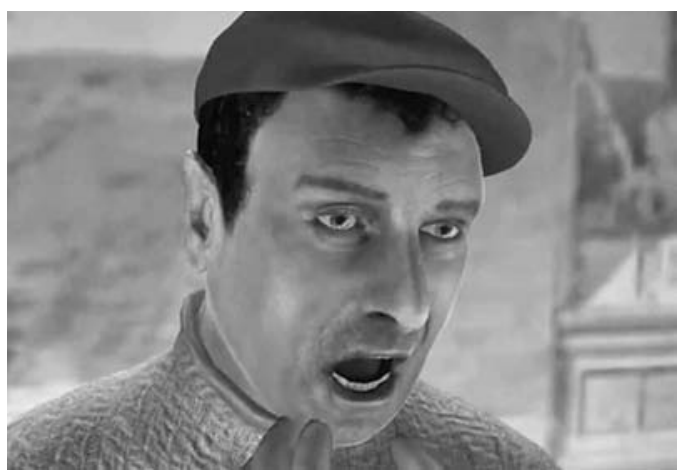

vivido pelo público no final do século XIX. Seleccionaram um típico teatro de vaudeville, o Union Square Theatre de B.F. Martin, em Nova lorque, no ano de 1895, recriando digitalmente aquele teatro juntamente com os seus clientes, intérpretes e restante pessoal. A Universidade da Georgia recebeu, em 2001, um subsídio de três anos no valor de 900.000 dólares para este projecto. Foram recriados digitalmente quatro números reais de vaudeville daquele período, baseados numa alargada pesquisa em arquivos: o homem forte Sandow o Magnífico, a cantora irlandesa Maggie Cline, o cómico Frank Bush e a breve comédia dos quatro Cohans, cujo membro mais novo, George M. Cohan, se viria a tornar uma das grandes estrelas da Broadway no início do século XX (cf. Saltz 2004: 30-37).

Estes espectáculos simulados podem ser vistos de dois modos diversos. Num deles, o modo da "câmara invisível", o espectador pode deslocar-se no espaço a três dimensões para observar o espectáculo do ângulo que preferir, incluindo a partir do palco. É também possível aproximar a câmara ao nivel de alguns pormenores, em palco ou fora dele, tais detalhes do figurino de um intérprete, decorações nas paredes do teatro, particularidades dos estofos das cadeiras, etc. 0 modo alternativo envolve aquilo que é talvez a dimensão mais inovadora e ambiciosa deste projecto, o público simulado. Um típico público de matiné no teatro chegaria aos 800 espectadores, e os investigadores procuraram atingir este objectivo ambicioso de, tanto quanto possivel, reflectir a distribuição por sexo, classe social e etnia do seu público virtual pelas diferentes partes do auditório. 0 objectivo não foi assim unicamente o de "ocupar os lugares com rostos e figurinos historicamente rigorosos e convincentes", mas também o de animar cada figura "de forma a reagir a cada momento de cada número de um modo consistente com o seu perfil demográfico". Assim, "quando Frank Bush interpreta o seu personagem irlandês, os espectadores irlandeses na galeria - um grupo particularmente barulhento - devem responder de modo 


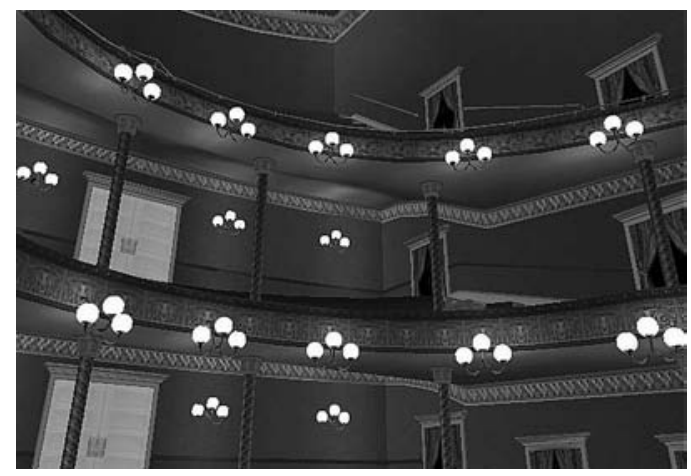

muito diferente dos espectadores brancos, anglo-saxónicos e protestantes, instalados nos camarotes" (Saltz 2004: 35).

A operação tão minuciosa de 800 espectadores individuais revelou-se demasiado dificil de criar ou de programar, razão pela qual se optou pela criação de 32 grupos básicos de espectadores, tais como um de homens brancos, anglo-saxónicos e protestantes de classe alta e um outro de mulheres afro-americanas de classe média, com reacções animadas para cada um dos grupos. A isto foram acrescentadas entre três e cinco variações físicas no rosto e nas roupas de cada grupo, complementarmente diversificados através de variações nos chapéus e nos pelos faciais. É possivel ao utilizador seleccionar quatro espectadores específicos, ou "avatares", de modo a ver o espectáculo através dos seus olhos em alternativa ao modo da "câmara invisivel". Cada um deles representa um grupo sócio-económico diferente: a Sra. Dorothy Shoper é uma colunável abastada a assistir ao espectáculo com a sua filha; o Sr. Luigi Calzilaio é um imigrante italiano recémchegado, acompanhado pelo seu irmão já mais americanizado; o Sr. Jake Spender é um jovem divertido e folgazão, sentado ao lado de uma corista; e a Menina Lucy Teacher é uma professora afro-americana, acompanhada pelo seu namorado e sentada no mais segregado segundo balcão. 0 utilizador pode deslocar a cabeça do avatar de modo a concentrá-la em diferentes áreas do palco ou do auditório e pode ainda accionar um conjunto limitado de reacções, incluindo o riso, o aplauso ou, por vezes, o diálogo com a pessoa sentada a seu lado. 0 utilizador selecciona uma reacção genérica e o sistema assegura uma mais especifica, levando em conta aquilo que se está a passar no palco e as anteriores reacções do espectador, de modo a que cada experiência do espectáculo resulte num acontecimento único.

Este tipo tão elaborado de ambiente simulado sugerido pelo projecto Virtual Vaudeville requer claramente um investimento considerável de tempo e de recursos físicos,

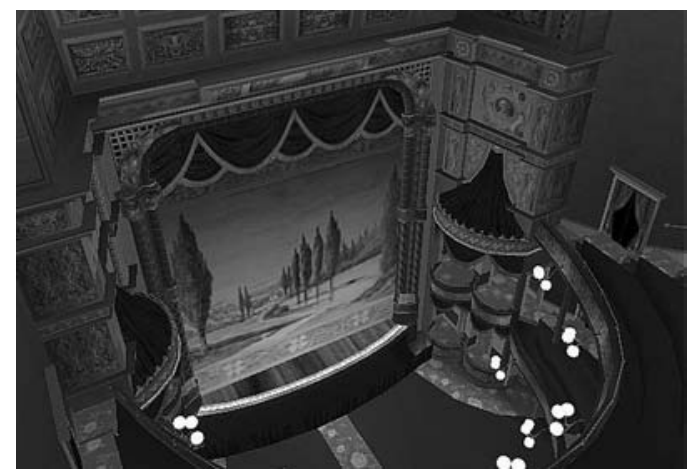

$<>$ www.virtualvaudeville.com

mas a evolução rápida da tecnologia digital e dos programas de simulação garante que, no futuro, veremos cada vez mais programas deste tipo, e parece muito provável que, tal como o Professor Saltz e os seus colegas prevêem, estas simulações venham a tornar-se uma ferramenta muito importante tanto na visualização de espectáculos históricos como no teste de hipóteses sobre algumas práticas históricas no domínio da representação teatral.

A criação de um espectáculo histórico virtual, com um tão elevado número de pormenores, é um dos exemplos mais extraordinários e "espectaculares" das actuais aplicações da tecnologia digital à investigação histórica, mas não é certamente o único, nem talvez o mais caracteristico. Um outro importante desenvolvimento é o estabelecimento de ligações entre materiais instalados em vastas bases de dados relacionais, de modo a que o investigador não fique limitado ao modelo linear mais tradicional da informação analógica, mas possa antes explorar uma vasta gama de materiais relacionados e ligados através do hipertexto digital. 0 estudo do teatro pode beneficiar muito deste tipo de desenvolvimento, uma vez que cada espectáculo envolve múltiplos criadores, criações e trajectórias. Assim, o estudo de um único espectáculo teatral tradicional pode implicar a consideração das contribuições dos actores, dos músicos, dos autores, dos compositores, dos coreógrafos, dos figurinistas, dos cenógrafos, dos aderecistas, dos desenhadores de luz e de som, dos encenadores e dos produtores, já para não falar dos técnicos e, já agora, dos próprios espectadores. Não só todos estes participantes precisam de ser levados em conta na compreensão de um único espectáculo, como, além disso, cada um deles deveria estar relacionado com muitos outros espectáculos, actividades sociais e culturais e objectos físicos. No passado, isto foi feito de um modo dominantemente linear, pesquisando certas áreas da actividade em detrimento de outras, deixadas para novas ${ }^{6}$ www.virtualvaudeville. oportunidades ou para outros investigadores. 

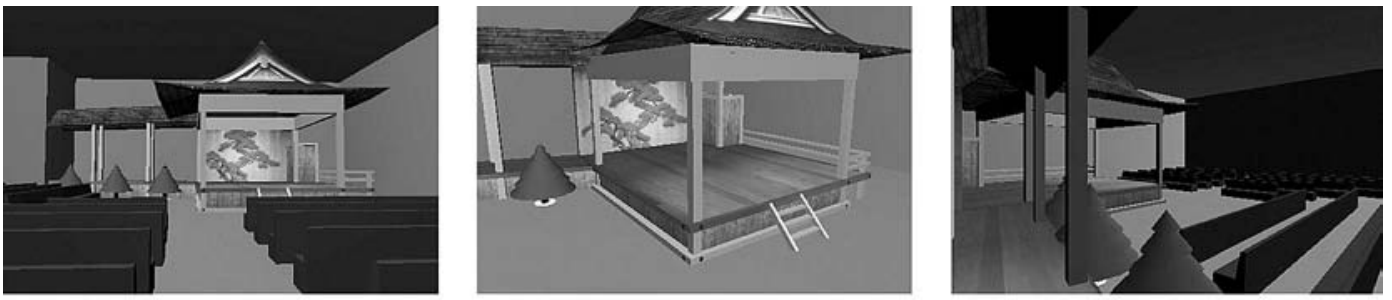

www.meyerhold.org
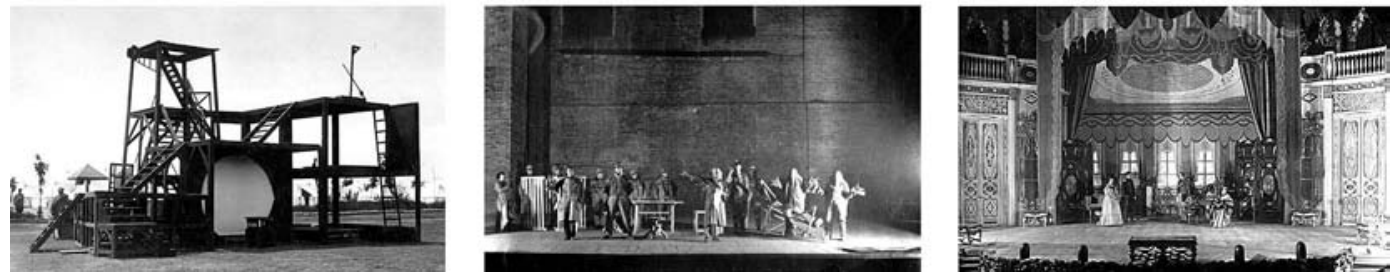

Mesmo uma base de dados relacional tão limitada como a do projecto Philadelphia, de Wolcott, sugere o modo como a tecnologia digital pode revolucionar esta investigação, já que uma qualquer dimensão de um espectáculo pode ser ligada a uma outra, bem como a uma rede potencialmente infinita de outros dados. $\dot{A}$ medida que os arquivos, as bibliotecas e os teatros em todo o mundo vão criando cada vez mais repositórios de material digital e redes mais complexas para interligar esse material, a investigação de teatro pode, cada vez mais, funcionar dentro do tipo de rede para a qual Wolcott assegurou unicamente uma proposta muito preliminar e rudimentar. Entre os muitos grupos envolvidos no desenvolvimento de uma rede desse tipo encontra-se o Consórcio Global das Artes do Espectáculo (Global Performing Arts Consortium/GloPAC), uma organização internacional de instituições e indivíduos criada em 1998 e empenhada na utilização de tecnologias digitais inovadoras para a disponibilização de recursos informativos acessiveis, multimédia e multilingues, para o estudo e preservação das artes do espectáculo. Entre os participantes deste projecto encontramos importantes universidades como a de Cornell, de onde partiu o projecto, museus, como o Museu Estadual de Teatro e Música de S. Petersburgo, o Museu da Cidade de Nova lorque e a Biblioteca das Artes do Espectáculo de São Francisco, e organizações ligadas às artes do espectáculo, como a Sociedade da Ópera Chinesa, de Singapura, e a Fundação Internacional para as Artes, do Japão.

0 GloPAC está actualmente envolvido em dois grandes tipos de projectos, ambos visando a disponibilização de recursos altamente flexíveis para investigadores dedicados às artes do espectáculo. 0 maior desses projectos é a Base de Dados Global das Artes do Espectáculo (Global Performing Arts Database/GloPAD), disponível ao público on-line. Nesta base de dados protótipo, o investigador pode procurar por determinadas peças e encontrar ligações a diversas produções. Ligações adicionais permitem ao investigador encontrar informação sobre actores e outras serão desenvolvidas redes cada vez mais complexas de recuperação de dados, de modo a permitir a um qualquer utilizador o visionamento de mais camadas de informação pormenorizada de acordo com os seus interesses específicos. Existe igualmente uma função para "folhear", que permite ao utilizador aceder a materiais de uma particular região geográfica, tal como Singapura ou o Japão, ou um assunto específico, tal como os figurinos dos criados.

O segundo grande projecto do GloPAC consiste na criação de Centros de Recursos sobre Artes do Espectáculo (Performing Arts Resource Centers/PARCs), ambientes destinados à internetque combinam conteúdos académicos com a sofisticação tecnológica, conduzindo o utilizador de volta ao GloPAD para explorar camadas adicionais de informação. Foram já desenvolvidos dois protótipos dos PARCs, um centrado no Japão ${ }^{8}$ e um outro no trabalho de Meyerhold ${ }^{9}$. O PARC japonês inclui um texto interactivo da peça de teatro nô Atsumori, acompanhada de uma tradução inglesa a meio do ecrã, o texto japonês à direita, as notas e o glossário em baixo, e imagens interactivas à esquerda, ligadas ao glossário e ao GloPAD. Este PARC também inclui material como uma apresentação de diapositivos sobre "Criar Figurinos para o Guerreiro do Teatro Nô" e um modelo interactivo em três dimensões de um palco de teatro nô. Estas apresentações promovem um processo novo, de base digital, de "leitura", permitindo aos utilizadores a exploração e a combinação de materiais de formas muito variadas, em função dos seus interesses. Dada a ambição destes vários projectos representativos, o trabalho desenvolvido até ao momento é ainda uma parte minúscula daquilo que eles esperam vir a oferecer, consistindo na sua maior parte em modelos e protótipos. Deve ser lembrado, contudo, que o campo da investigação digital em teatro é ainda extremamente recente - o trabalho pioneiro de Wolcott não foi há mais de vinte anos e todo os outros projectos que antes descrevi foram lançados nos últimos anos. A primeira conferência dedicada à documentação de recursos sobre artes do espectáculo em ambiente virtual, cujas actas me foram extraordinariamente úteis na preparação deste relatório, foi realizada a 10 de Outubro de 2003 na Biblioteca Pública para as Artes do Espectáculo, instalada no Lincoln Center. Ai, mais de uma centena de arquivistas, curadores, educadores, bibliotecários, criadores, professores e estudantes partilharam informação sobre esta nova área dos estudos de teatro em tão rápida expansão (cf. Schlesinger 2004) ${ }^{10}$ 

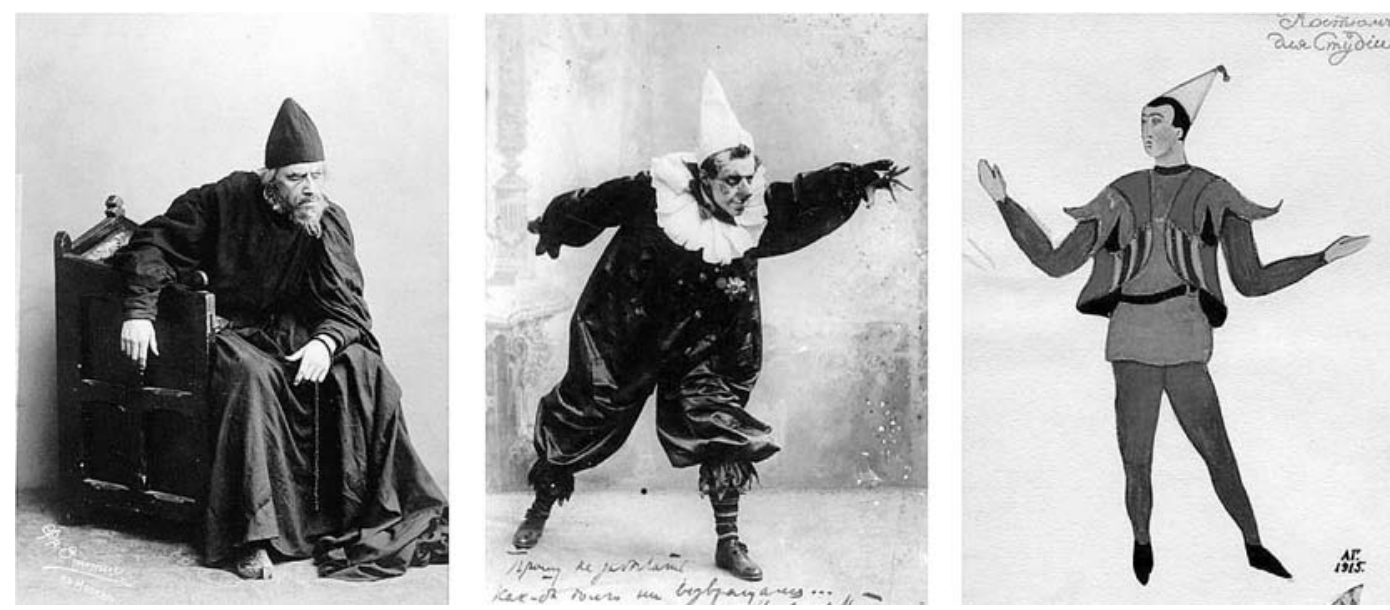

Parece quase certo que neste século que agora se inicia, estes bancos de dados espalhados e estes protótipos se revelarão como apenas o início de um novo modo de documentar o espectáculo e de o estudar. Ao mesmo tempo, este admirável novo mundo digital apresenta sérios problemas para futuros investigadores de teatro, de modo algum limitados aos mais óbvios relacionados com a quantidade quase infinita de material que poderia potencialmente ser incluída num qualquer banco de dados. Em meados dos anos noventa do século passado, a comunidade bibliotecária começou a preocupar-se com um outro problema resultante da crescente digitalização de materiais de arquivo, a preservação de trabalhos armazenados em suporte digital. Em Dezembro de 1994, a Comissão para a Preservação e Acesso e o Grupo de Bibliotecas de Investigação criou um Grupo de Trabalho sobre Arquivos Digitais composta por indivíduos provenientes da indústria, dos museus, dos arquivos e bibliotecas, das associações universitárias e do governo. A sua tarefa era a de investigar os meios de assegurar "a continuidade do acesso futuro aos registos armazenados em suporte digital". Este Grupo de Trabalho avançou com uma série de exemplos alarmantes de dados históricos importantes irremediavelmente perdidos e avisou que "mudanças rápidas nos meios de gravar informação, nos suportes do seu armazenamento e nas tecnologias utilizadas ameaçam tornar a vida da informação na era digital em algo, para usar uma frase de Hobbes, de 'horrivel, rude e breve'"'11. Preocupações semelhantes foram partilhadas com um público mais alargado através de um ensaio publicado na Scientific American, "Ensuring the Longevity of Digital Documents", escrito por Jeff Rothenberg, investigador da Rand Corporation (cf. Rothenberg 1995).

Howard Besser, um membro deste Grupo de Trabalho, tornou-se uma das principais autoridades nesta matéria. Ele é actualmente chefe do Programa de Arquivamento e Preservação da Imagem em Movimento, da Universidade de Nova lorque, e já participou em diversos Conselhos Nacionais sobre a preservação de registos electrónicos. Uma das formulações mais completas e sucintas sobre as várias dimensões deste problema pode ser lida no artigo de Besser, "Digital Longevity", integrado numa recolha de ensaios, The Handbook for Digital Projects, publicada em 2000 pelo Northwest Document Conservation Center. Nesse artigo, Besser apresenta os diversos problemas ligados à investigação e ao acesso resultantes da emergência da tecnologia digital. Há actualmente uma consciência alargada entre a comunidade de investigadores sobre estes problemas e muitas tentativas para lhes responder, embora todas elas, até ao momento, com sucesso limitado. A sua persistência sugere que à medida que arquivistas, investigadores e historiadores se empenham mais nesta tecnologia, como parece inevitável que aconteça, teremos ao mesmo tempo de nos manter conscientes destes problemas e da medida em que eles qualificam as aplicações a curto prazo e, talvez ainda mais significativamente, a longo prazo da tecnologia digital. 0 problema mais óbvio no armazenamento de toda a informação electrónica, conhecido de quase todos hoje em dia, é a rápida obsolescência dos suportes físicos de armazenamento. Nos nossos escritórios e talvez nas nossas casas, assistimos em poucos anos à passagem dos discos de 8 polegadas para as disquetes de 5,25 polegadas, depois para as disquetes de 3 polegadas, depois para os CD-ROMs e para os DVDs. Recentemente, ao comprar um computador portátil, tive de comprar uma ligação especial para poder ter acesso às disquetes de 3 polegadas, condenadas já ao esquecimento. Este problema complica-se quando pensamos não só nos ficheiros de texto convencionais, mas também nos muito mais vastos ficheiros de imagem e vídeo, tão importantes na investigação em teatro e artes do espectáculo. Isto, juntamente com forças económicas, alimenta uma busca incessante por instrumentos de armazenamento mais vastos e mais poderosos, muitas vezes incompatíveis com suportes anteriores. A solução para este problema, proposto no relatório de 1996, foi aquilo que ficou conhecido como "refrescamento", a deslocação periódica de material de uma unidade fisica de armazenamento para uma outra, de modo a evitar a degradação física (até mesmo os CD-ROMs se deterioram) e, talvez mais importante, a obviar a obsolescência do próprio meio utilizado. A forma mais comum de "refrescamento" é aquela que recebeu o nome de "migração", traduzida na simples regravação do material em novos sistemas de armazenamento, à medida que eles vão aparecendo. Esta é talvez a melhor solução actualmente disponivel para projectos como o Theatron ou o Virtual Vaudeville, mas uma vez que ambos se apresentam como projectos piloto, não é difícil de nos imaginarmos chegados a um momento em que não é possivel acrescentar mais nenhum novo material, uma vez que de outro modo todo o tempo e esforços dos coordenadores do projecto seria dedicado à actualização de ficheiros. Neste momento, não http://www.rlg.org/ ArchTF/tfadi.index.htm\# fragility

${ }^{12}$ www.kb.nl/coop/nedlib/ results/emulation preservationreport.pdf 
há nenhuma alternativa clara. Alguns teóricos, nomeadamente Jeff Rothenberg, estão a trabalhar no sentido do desenvolvimento de uma alternativa à migração chamada "emulação". Isto implicaria o desenvolvimento de um programa de software capaz de mimetizar todas as outras aplicações num qualquer outro formato e de as tornar compativeis com qualquer ambiente de computador. Até agora, a pesquisa mais alargada neste domínio das estratégias de "emulação" tem sido aquela conduzida pela Networked European Deposit Library (NEDLIB). Esta organização tem dado passos importantes na codificação da informação digital numa grande variedade de formatos acessiveis através da sua rede europeia, mas por enquanto dedicou ainda escassa atenção ao problema da preservação, apoiando-se numa espécie de variação do extremamente moroso processo de "migração". Em 1999, a Biblioteca Nacional da Holanda encomendou à RAND-Europa que lançasse uma série de estudos sobre o desenvolvimento da tecnologia de "emulação". Os resultados da primeira fase destes estudos estão disponíveis na página daquela Biblioteca Nacional'2. Sugerem que através da criação de um programa de emulação espiralado, capaz simultaneamente de ler novos formatos e de manter o acesso às suas versões anteriores, não obrigando a repetir anteriores descodificações, parece possível, pelo menos teoricamente, o desenvolvimento de um programa contínuo de emulação. As dificuldades técnicas e legais desta estratégia são, contudo, grandes e enquanto a pesquisa continua, a migração impõe-se como a única alternativa de armazenamento no futuro imediato.

0 problema do refrescamento afecta qualquer sistema de arquivamento e de investigação em suporte digital, mas quando passamos de ambientes de teatro virtual ou de acontecimentos teatrais simulados como o Theatron e o Virtual Vaudeville para grandes bases de dados em rede como a GloPAC, o projecto Philadelphia ou o Hemispheric Institute, surge um problema adicional. Os primeiros são essencialmente programas fechados, enquanto que os segundos, embora possam possuir determinados bancos de dados, são sobretudo úteis como guias para redes mais vastas de material interrelacionado espalhado pelo hiperespaço. Qualquer página na internetcontém, habitualmente, ligações para outras páginas, e estas bases de dados procuram alargar essa capacidade até à sua extensão máxima, ligando muitos aspectos da experiência teatral a informações relacionadas tanto dentro como fora do teatro. Aqui surge um outro problema electrónico que Besser aborda no seu artigo "Digital Longevity" e que ele caracteriza como "o problema interrelacional" (Besser 2000: 160). 0 problema aqui é que estas localizações ligadas entre si são extremamente instáveis. 0 arquivista da Internet Brewster Kahle, director e co-fundador do Internet Archive, uma biblioteca digital de sítios na internet e de outros artefactos culturais em suporte digital ${ }^{13}$, relatou no número de Março de 1997 da Scientific American que, nessa altura, o documento da internet médio durava unicamente 75 dias (Kahle 1997: 53). A mensagem mais comum hoje em dia na World Wide
Web é "Ficheiro não encontrado" ou "Esta página não pode ser apresentada", indicando que aquela ligação já não existe. A compilação de bancos de dados volumosos e fechados como o Internet Archive, cada um dos quais presumivelmente responsável pela actualização electrónica do seu material externo, oferece simplesmente uma solução parcial para este problema, uma vez que projectos como - GloPAC não podem começar a alcançar o seu objectivo de abrangência enquanto se limitarem unicamente a material digital contido dentro do seu próprio sistema.

Assim, a situação actual apresenta-nos um quadro desafiador e complexo do futuro da investigação de teatro num mundo digital. Por um lado, a tecnologia actual põe à disposição dos investigadores presentes e futuros oportunidades de acesso a materiais e de construção de modelos históricos com as quais os estudantes de teatro de há uma geração ou duas atrás dificilmente sonhariam. Por outro lado, estas fantásticas novas possibilidades arrastam consigo fantásticos novos problemas nos modos de acesso, manipulação e até mesmo de conservação das vastas quantidades de informação e de perspectivas que estas oportunidades prometem. As negociações entre estas novas oportunidades e estes novos desafios serão seguramente uma das principais preocupações dos investigadores de teatro no século que agora se inicia.

\section{Referências bibliográficas}

BESSER, Howard (2000), "Digital Longevity", in Maxine K. Sitts (ed.), The Handbook for Digital Projects, Andover, Massachusetts, The Northeast Document Conservation Center, pp. 155-66. (Também disponivel em: http://www.nedcc.org/digital/tofc.htm)

DENARD, Hugh (2004), "Performing the Past: The Virtual Revolution in Performance History", in Kenneth Schlesinger (ed.), Performance Documentation and Preservation in an Online Environment, Performing Arts Resources, vol. 24, New York, Theatre Library Association, pp. 5470.

KAHLE, Brewster (1997), "Archiving the Net", Scientific American, vol. 276, n. 3 , Março, p. 53.

ROTHENBERG, Jeff (1995), "Ensuring the Longevity of Digital Documents", Scientific American, vol. 272, n. ${ }^{1}$, Janeiro, pp. 42-47.

SALTZ, David Z. (2004), "Virtual Vaudeville: A Digital Simulation of Historical Theatre", in Kenneth Schlesinger (ed.), Performance Documentation and Preservation in an Online Environment, New York, Theatre Library Association, pp. 30-37.

WOLCOT, John R. (1990) "Learning Theatre History in the 3rd Dimension", Theatre Design and Technology, vol. 26, n. ${ }^{\circ}$, Outono, pp. 51-54.

Este artigo é a tradução da conferência proferida a 26 de Abril de 2005 na Faculdade de Letras de Lisboa, no âmbito da acção do Centro de Estudos de Teatro, "História do Teatro e Novas Tecnologias" que, para esta iniciativa, teve o apoio da Fundação para a Ciência e a Tecnologia (FCT) e da Fundação Luso-Americana para o Desenvolvimento (FLAD).

Tradução de Paulo Eduardo Carvalho 